\title{
Application of thermal imaging to assess the superficial skin temperature distribution after local cryotherapy and ultrasound
}

\author{
Ewa Boerner ${ }^{1} \cdot$ Halina Podbielska ${ }^{2}$ (D)
}

Received: 4 June 2017/ Accepted: 19 October 2017/Published online: 26 October 2017

(C) The Author(s) 2017. This article is an open access publication

\begin{abstract}
Thermal imaging is a safe, noninvasive, and quite low-cost technique that allows for the rapid and noninvasive recording of thermal radiation emitted by the human body. In recent years, it is increasingly used for physiotherapy monitoring. The main goal of the study was to compare the influence of two various treatments applied in two various orders, namely local cryotherapy (CRYO) and ultrasound therapy (US). The impact of combined therapies, applied in two various orders, was studied in terms of changes of the superficial temperature distribution on the front right thigh surface. The response to the therapy depending the treated persons' gender, along with a consensual reaction, was examined. The research material consisted of 30 healthy volunteers, 19-23-year old students, aged $19.93( \pm 1.42)$. All treatments were performed at weekly intervals in the following order: in the first week, CRYO immediately followed by US, and in the second week, ultrasound immediately followed by local cryotherapy. All treatments were performed on the right quadriceps. The combined sequence of local cryotherapy and ultrasound therapy caused temperature decrease in the treated area regardless of their performance order. The temperature decrease considerably depends on the sequence of the applied treatments, and it was more significant after the ultrasound-cryotherapy sequence.
\end{abstract}

Ewa Boerner

ewa.boerner@awf.wroc.pl

1 Faculty of Physiotherapy, University School of Physical Education, Al. I. J. Paderewskiego 35, 51-612 Wrocław, Poland

2 Department of Biomedical Engineering, Faculty of Fundamental Problems of Technology, Wrocław University of Science and Technology, Wybrzeże Wyspiańskiego 27, 50-370 Wrocław, Poland
Moreover, these changes also lasted longer. Statistically significant influence of the subjects' gender was observed in case of consensual reaction.

Keywords Thermal imaging - Local cryotherapy · Ultrasound · Physiotherapy

\section{Introduction}

Body temperature is one of the most commonly used indicators of health status in humans. Thermal imaging for the superficial temperature measurement has been used since the early 1960s in various fields. Recent technical advances in infrared cameras open new possibilities [1]. Thermal imaging is a safe, noninvasive, and quite inexpensive technique that allows for the monitoring of the superficial body temperature for various applications [2-5]. Furthermore, thermal imaging enables to specify temperature changes not only in terms of values, but also in terms of spatial distribution, what can be exploited in various biomedical applications [5-7]. The spatial distribution of temperatures is associated with the spatial distribution of the energy emitted from the examined body. The thermal imaging enables to determine the temperature in each point on the surface basing on the recording of the spatial distribution of the emitted energy.

In physical medicine, various physical stimuli to evoke beneficial effects in the human body are used. Many physical agent modalities cause changes in the superficial and deep tissue temperature [8,9]. Properly chosen physical agent should lead to a specific reaction with a desired effect. When recommending physical treatment, two or three modalities are very often administered to be executed in one session. These treatments, causing various thermal 
effects, are often performed one after another [10]. As a general rule, the order of such polytherapy is random, because there is little information regarding the correct sequence. These physical treatment modalities may act synergistically or antagonistically one to another. Individual characteristics of a patient, such as sex and age, or even body mass, should also be taken into consideration. Therefore, temperature distribution after the application of the selected physical factors, change in tissue temperature values and, in particular, the period after which the temperature returns to its initial value, should be assessed.

Local cryotherapy and ultrasound therapy (called sonotherapy) are applied in physical treatment for their analgesic and anti-inflammatory effects. These two treatments are often recommended in one session. Local cryotherapy is the stimulating application of low temperatures around $-100 /{ }^{\circ} \mathrm{C}$ or slightly below for $1-3 \mathrm{~min}$. Cryotherapy supports basic treatment and facilitates kinesiotherapy. From the clinical standpoint, local cryotherapy has analgesic, anti-inflammatory, antioedematous effects and reduces muscle tone [11-14].

In sonotherapy, the ultrasound waves with frequency between 0.8 and $3.0 \mathrm{MHz}$ and power density not exceeding $3 \mathrm{~W} / \mathrm{cm}^{2}$ are used as physical agent. Many biophysical changes comprising thermal, mechanical, and physicochemical effects occur in the body under the influence of the ultrasonic waves. These include analgesic activity, muscle relaxing, vasodilation, stabilizing the sympathetic nervous system, inhibiting the inflammatory processes [15]. The therapeutic effect of physiotherapy may be monitored by analyzing temperature changes on the superficial tissues [16-20].

The aim of this study was to compare the impact of the sequence of local cryotherapy and sonotherapy, applied immediately one after another, on the superficial temperature distribution on the front right thigh surface. The impact of combined therapies, applied in two various orders, was studied in terms of changes of the superficial temperature distribution on the front right thigh surface. The responses to the therapy depending the treated persons' gender, along with a consensual reaction, were examined.

\section{Study material}

The study group consisted of 30 healthy, nonsmoking, volunteers including 17 women (57\%) and 13 men (43\%), aged 19-24 years (Table 1). Participants enrolled into the study were informed about the experiment and gave their consent to participate in the research. In order to conduct the study, approval from the Senate Commission of
Table 1 Age distribution in the study group

\begin{tabular}{llllll}
\hline Sex & Number of subjects & \multicolumn{4}{l}{ Age/years } \\
\cline { 3 - 6 } & & Mean & Minimum & Maximum & SD \\
\hline Women & 17 & 19.7 & 19 & 22 & 0.8 \\
Men & 13 & 20.2 & 19 & 24 & 1.4 \\
Total & 30 & 19.9 & 19 & 24 & 1.1 \\
\hline
\end{tabular}

Bioethics of the Wrocław University School of Physical Education in Wroclaw was obtained on March 19, 2012.

Regarding the body mass index (BMI), these groups were quite homogenous: BMI did not vary significantly statistically in the examined women and men $(t=0.59$, $p=0.56>0.05)$. All examined persons were characterized by a BMI value within the norm (18.8-24.9) (Table 2).

\section{Study methods}

Each volunteer was subjected to treatments in the following order: in the first week local cryotherapy treatment, directly followed by ultrasound. The sequence was named CRYO-US. In the second week, ultrasound immediately followed by local cryotherapy was applied. The sequence was called US-CRYO. The body area subjected to physiotherapeutic treatments was the right quadriceps. The treated place on the thigh was situated $10 \mathrm{~cm}$ above the kneecap top and $15 \mathrm{~cm}$ below the groin.

Kriotel apparatus from Wrocław, Poland, was used for local cryotherapy. The treatment lasted $3 \mathrm{~min}$. The temperature at the nozzle outlet was $-156^{\circ} \mathrm{C}$, reaching approximately $-100{ }^{\circ} \mathrm{C}$ on the skin. The ultrasound was applied by means of Ionoson apparatus from Physiomed, Germany. The dose applied was $0.6 \mathrm{~W} / \mathrm{cm}^{2}$ with $1 \mathrm{MHz}$ frequency, and the treatment lasted $6 \mathrm{~min}$. The coupling substance was liquid paraffin, Avena, Poland. The physiotherapeutic treatments were executed by the same person

Table 2 Body characteristics of women and men in the study group

\begin{tabular}{llrlll}
\hline Characteristics & Sex & Mean & Minimum & Maximum & SD \\
\hline Height/cm & Women & 169.1 & 158 & 178 & 5.3 \\
& Men & 183.1 & 174 & 190 & 5.0 \\
Body mass/kg & Women & 61.6 & 47 & 73 & 6.6 \\
& Men & 73.2 & 64 & 90 & 7.2 \\
BMI $^{\mathrm{a}}$ & Women & 21.5 & 18.8 & 24.3 & 1.4 \\
& Men & 21.9 & 19.3 & 24.9 & 1.9 \\
Total & & 21.6 & 18.8 & 24.9 & 1.6 \\
\hline a $B M I$ body & & &
\end{tabular}

${ }^{\mathrm{a}} B M I$ body mass index (body mass divided by body height $/ \mathrm{kg} \mathrm{m}^{-2}$ ) 
in accordance with the generally accepted rules. All experiments were performed in the same therapy room and under the same conditions. The room temperature was $24 \pm 1.0{ }^{\circ} \mathrm{C}$, and the humidity was $39 \pm 1.0 \%$.

Temperature changes were examined by means of a thermal imaging camera FLIR $T_{335}$. Prior to the study, the volunteers were not subjected to any intense physical strain or physical treatments. Each participant adapted to the conditions for a period of $20 \mathrm{~min}$, by exposing the uncovered treated area to the room conditions. Infrared images were recorded in a standing position at the distance $1.2 \mathrm{~m}$ from the camera. The optical axis of the camera was perpendicular to the center of the treated spot. Five thermal images were recorded for each participant in the first week and in the second week.

For each image, a region of interest ROI was determined, corresponding to the treatment area, as described above. The mean, maximal, and minimal temperatures in ROI were analyzed. As the obtained data follow normal distribution, the Student's $t$ test for dependent samples was used for statistical analysis. The influence of gender dimorphism was analyzed by means of Student's $t$ test for independent samples. The correlation of the results with consensual reaction was calculated with the help of Pearson's coefficient $r$. For statistical analysis, the STATISTICA 10 software was used.

\section{Results and discussion}

\section{The relationship between the temperature changes and the treatments sequence}

Exemplary thermal images captured in the examination are depicted in Figs. 1 and 2.

The recorded thermal images, and further the data, were marked in the following manner: $\mathrm{T} 1$-before treatment, T2-immediately after the first treatment, T3-immediately after the second treatment, T4-15 min after the second treatment, T5-30 min after the second treatment. Thermal images in the rainbow pseudo-color scale were stored on a computer disk as the files in JPG format with a size of $340 \times 240$ pixels. The Therma CAM Researcher
2.9 software was used for analysis to find out mean, minimal, and maximal values of temperatures in the rectangular region of interest ROI.

The analysis of the initial temperatures on the right thigh front surface before treatments showed that these values were similar and did not differ significantly, independent of the examined sequence: the CRYO-US or the US-CRYO order. However, the significant changes were observed after treatments. Various therapy sequences resulted in various changes of the temperature (Fig. 3). Directly, after both treatments, regardless of their order, the mean thigh surface temperature changed in all examined persons (T2). The significant decrease in the temperature after CRYOUS sequence was observed (T2 dropped from 31.5 to $24.3^{\circ} \mathrm{C}$ ). For the US-CRYO sequence, slightly higher temperature was seen; however, this change was not statistically significant (T2 raised from 31.7 to $31.9{ }^{\circ} \mathrm{C}$ ). The mean $\mathrm{T} 3$ temperature was lower than mean $\mathrm{T} 1$. No further decrease was observed after the second treatment; however, T3 for the sequence US-CRYO was $5.1{ }^{\circ} \mathrm{C}$ lower than T3 for the CRYO-US order.

One can also see that the decrease in the examined temperature due to the US-CRYO treatment lasted longer than in the case of CRYO-US. After the treatment, an increase in the mean temperature between $\mathrm{T} 3$ and $\mathrm{T} 4$ is observed. However, it is higher for the US-CRYO sequence (from 25.2 to $30.4{ }^{\circ} \mathrm{C}$ ), while for CRYO-US it varies from 30.2 to $31{ }^{\circ} \mathrm{C}$. Table 3 depicts the examined changes, showing these statistically significant, for the significance level $p=0.001$. After last treatment (T3) and 15 min later (T4), the mean temperatures differences were statistically significant. After $30 \mathrm{~min}$ (T5), the difference in temperatures caused by CRYO-US and US-CRYO was not statistically significant $(p=0.056)$.

\section{The relationship between thigh surface temperature changes and gender}

The same analyses were performed for male and female participants separately. Before the treatment, the mean right thigh surface temperature in men was slightly higher than the mean thigh surface temperature in women. The difference between the initial mean values was $1.1{ }^{\circ} \mathrm{C}$, and (a)

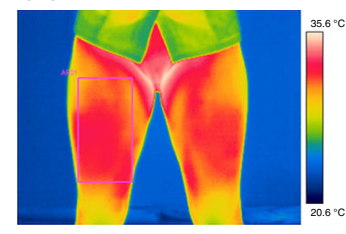

(b)

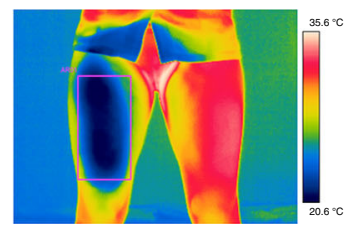

(c)

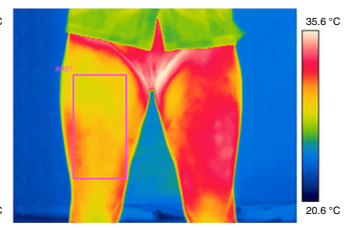

(d)

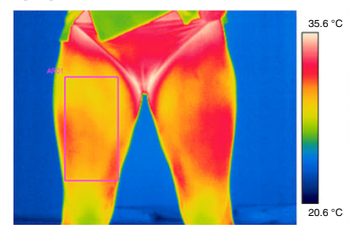

(e)

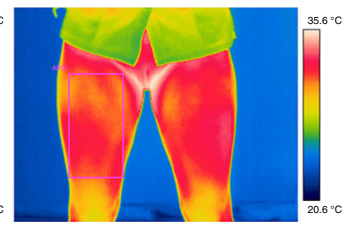

Fig. 1 Exemplary thermal images after combined CRYO-US (week I): a T1 before the treatment, b T2 after the first treatment, $\mathbf{c}$ T3 after the second treatment, d T4 15 min after the second treatment, e T5 $30 \mathrm{~min}$ after the second treatment 
(a)

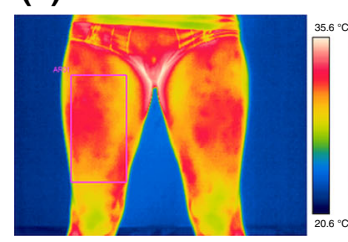

(b)

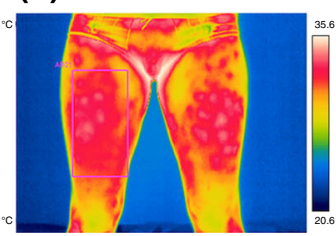

(c)

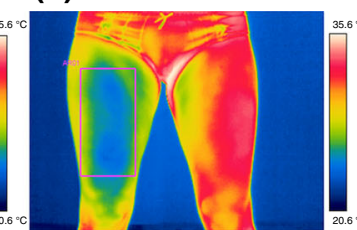

(d)

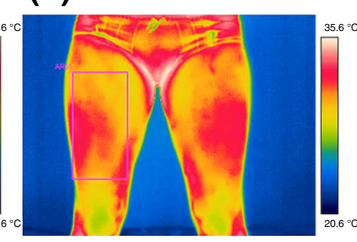

(e)

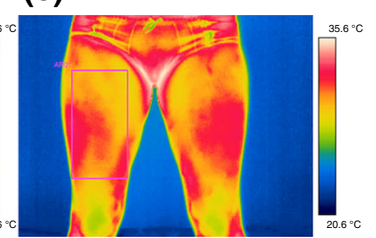

Fig. 2 Exemplary thermal images after combined US-CRYO (week II): a T1 before the treatment, b T2 after the first treatment, $\mathbf{c}$ T3 after the second treatment, d T4 15 min after the second treatment, e T5 30 min after the second treatment

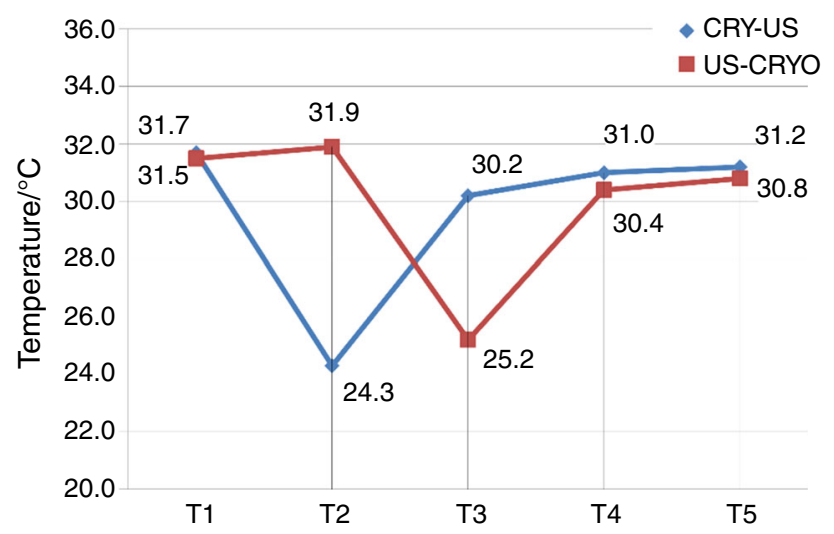

Fig. 3 Mean right thigh surface temperature in ROI for various treatment orders

it was statistically significant. No statistical differences between men and women were found when analyzing the therapy results. The trend was the same as for the entire group, meaning the statistically significant differences observed after last treatment (T3) and 15 min later (T4). However, in each time point, no statistical difference between genders was seen. The initial difference $1.1{ }^{\circ} \mathrm{C}$ between mean temperatures in men and women was similar in the entire experiment. No statistically significant differences in reaction to the therapy were found in the studied group of young volunteers (Fig. 4).

\section{Consensual reaction}

For various stimuli, a consensual response may be observed on contralateral side of the body, when the other side has been stimulated. For example, such reaction is seen in human eye pupil after the light exposure. Here, we examined mean temperature changes on the left thigh after the exposure of the right thigh to the US-CRYO and CRYO-US treatment sequences, to find out whether there is any consensual reaction.

As it was shown above, immediately after the treatment, the mean temperature of the right thigh was lower than the initial one (before treatment). The positively correlated consensual response should also follow this trend. However, it was observed only in some of the subjects, only when the temperature difference was higher than $-2{ }^{\circ} \mathrm{C}$. It was more evident in the case of the CRYO-US sequence than in the US-CRYO sequence. Thus, the consensual reaction appeared to be more evident in the CRYO-US sequence. The correlation factor of the surface temperature changes on both thighs after treatments and on the right thigh was equal $r=0.77$ and was statistically relevant $(p<0.001)$, whereas after the US-CRYO sequence, the correlation was significantly weaker, although it was also statistically relevant $(r=0.36 . p=0.047)$.

Studying this effect in women and men separately, it was stated that in women for CRYO-US sequence, the reaction is more visible, since $r=0.90(p=0.000001)$,

Table 3 Temperature changes after examined therapeutic sequences CRYO-US and US-CRYO (in bold—statistically significant results)

\begin{tabular}{|c|c|c|c|c|c|c|}
\hline \multirow[t]{2}{*}{ Measurement } & \multirow[t]{2}{*}{ Sequence } & \multicolumn{3}{|c|}{ Mean right thigh temperature in $\mathrm{ROI} /{ }^{\circ} \mathrm{C}$} & \multicolumn{2}{|c|}{ Student's $t$ test } \\
\hline & & Mean & Standard deviation & $\begin{array}{l}\text { The differences in the mean } \\
\text { temperatures for various sequences }\end{array}$ & $t$ & $p$ \\
\hline \multirow[t]{2}{*}{ After last treatment $\mathrm{T} 3$} & CRYO-US & 30.2 & 1.2 & 5.0 & 14.78 & $<0.001$ \\
\hline & US-CRYO & 25.2 & 1.7 & & & \\
\hline \multirow[t]{2}{*}{15 min after treatment $\mathrm{T} 4$} & CRYO-US & 31.0 & 1.0 & 0.6 & 3.60 & 0.001 \\
\hline & US-CRYO & 30.4 & 1.1 & & & \\
\hline 30 min after treatment $\mathrm{T} 5$ & CRYO-US & 31.2 & 0.9 & 0.3 & 1.99 & 0.056 \\
\hline
\end{tabular}


(a)

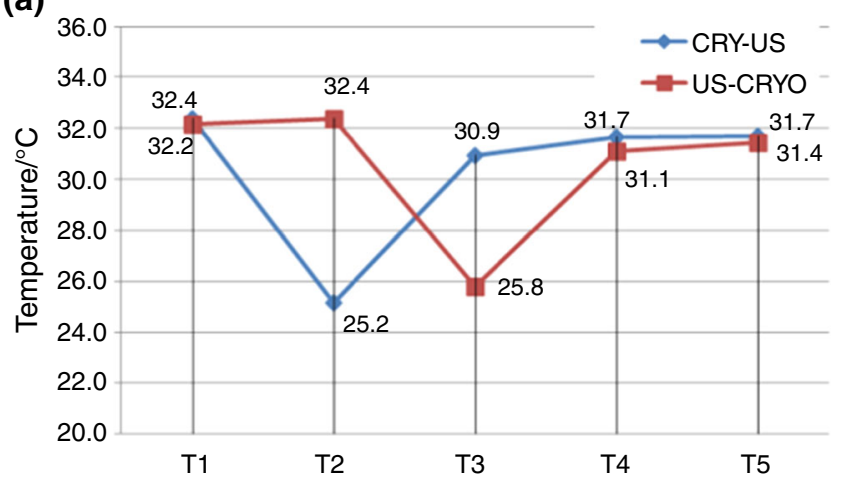

(b)

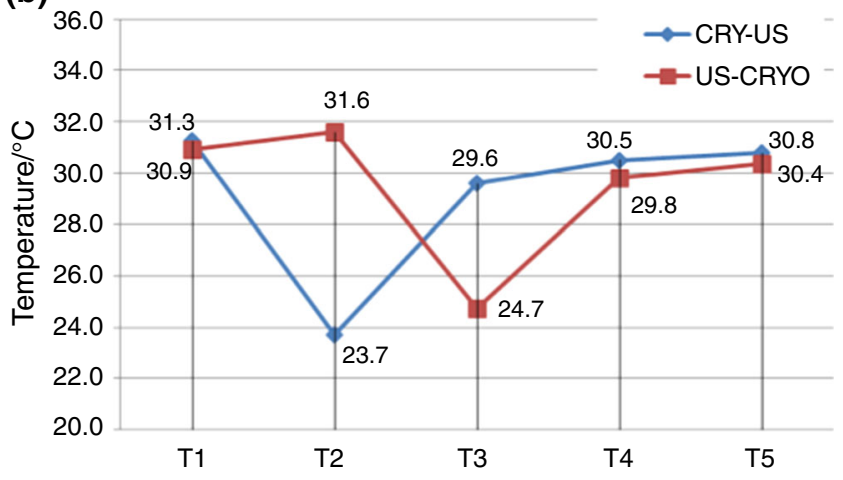

Fig. 4 Mean right thigh surface temperature in ROI for various treatment orders, depending on gender: men (a), women (b)

(a)

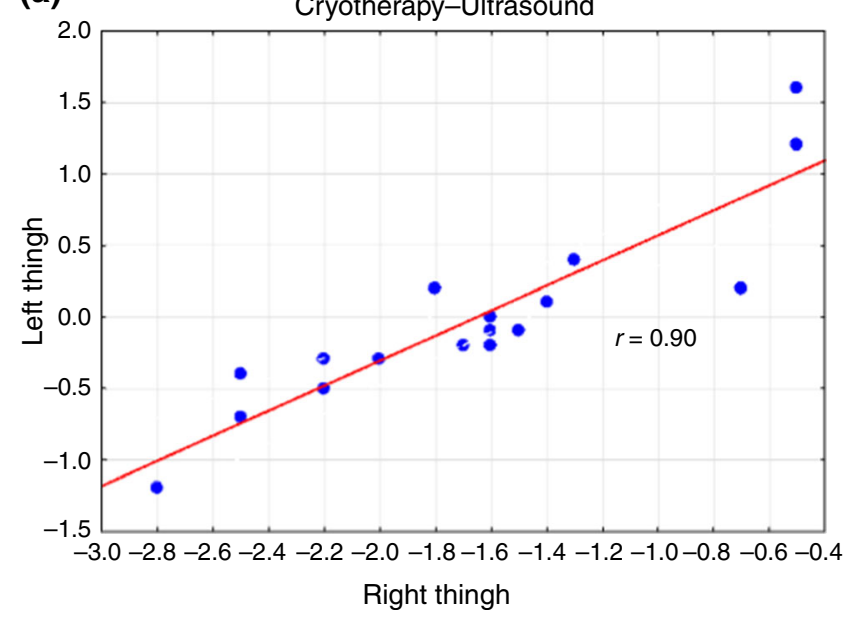

(b)

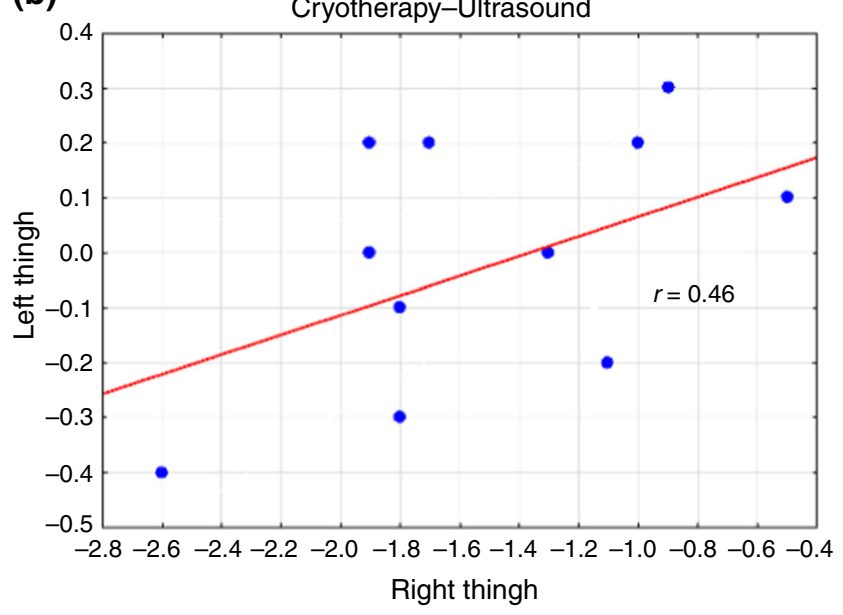

Fig. 5 Consensual reaction on the contralateral thigh, correlation coefficient $r$ in men (a) and women (b) after CRYO-US sequence

(a)

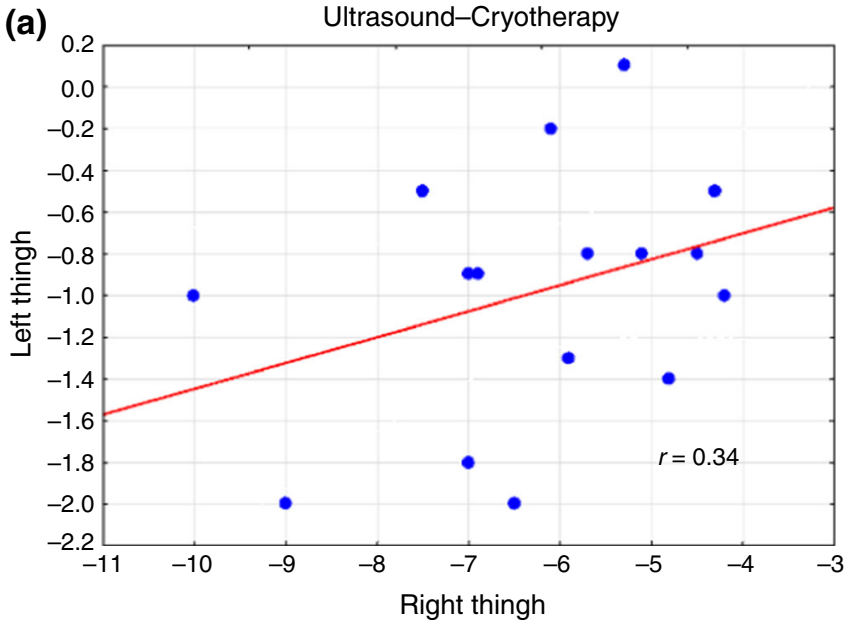

(b)

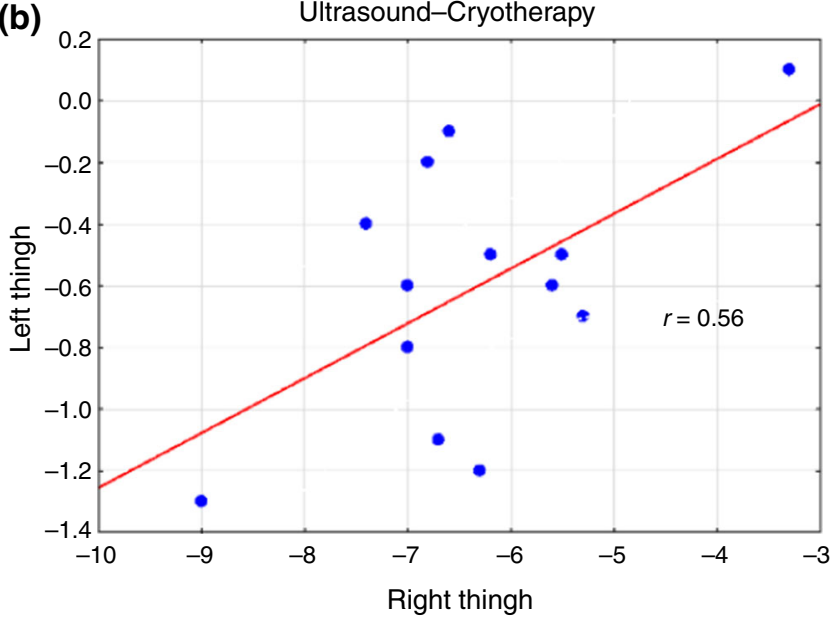

Fig. 6 Consensual reaction on the contralateral thigh, correlation coefficient $r$ in men (a) and women (b) after US-CRYO sequence

whereas in men the correlation is weak and statistically insignificant: $r=0.46 \quad(p=0.11) \quad$ (Fig. 5a, b, correspondingly).
The opposite effect was observed in case of US-CRYO sequence (see Fig. 6a, b). In women, the correlation was weak and statistically insignificant: $r=0.34(p=0.18)$, 
whereas in men the higher correlation was observed $r=0.56$ and it was statistically significant $(p=0.046)$.

Summarizing, quite similar consensual effect was observed in men for both therapy sequences, while in women that was higher for CRYO-US sequence. Consensual reaction may be an important factor in physiotherapeutic practice, since in some circumstances it can be regarded as an additional benefit or in other cases, it may negatively influence the therapeutic outcomes or even may be contraindicated. Physiotherapeutic stimuli are, e.g., not recommended in cancer patients in places near the pathological sites. But even remote application may evoke contralateral response. The consensual reaction is always less pronounced than the local one, directly exposed to the physical agent. In examined therapy sequences, this effect was minimal. Interesting that it was gender dependent, what may be explained by differences in fat distribution and skin vasculature.

In physical medicine, treatments applying various physical stimuli, e.g., thermal, electrical, optical, mechanical, or magnetic stimuli, are used. Most of them have thermal effects, resulting in a change of the temperature in the treated area [4]. Thermal imaging is one of the most sufficient methods of superficial temperature distribution examination [1-7, 13-20].

There are some publications describing the application of thermal imaging for the assessment of the physical treatment effectiveness [18-20]. However, as so far, no studies are reported describing temperature changes after combination of selected physical treatments and examining time interval, in which the temperature returns to initial values. To our best knowledge, the presented study was not described in the literature.

\section{Conclusions}

On the basis of the performed research, it was found that cryotherapy combined with ultrasound in one therapeutic session decreases the temperature in the treated area, irrespectively of the sequence of their performance. However, it was found that the temperature decrease depends significantly on the sequence of the applied treatments, and it was $5{ }^{\circ} \mathrm{C}$ higher after the US-CRYO sequence than CRYO-US. The difference between the mean values clearly decreased within $15 \mathrm{~min}$ after the treatments, but still the mean thigh surface temperature after the USCRYO treatment sequence was significantly lower than the mean temperature after the CRYO-US sequence. On the other hand, $30 \mathrm{~min}$ after the treatments, the mean surface temperature values were not different in terms of statistical relevance, but they still remained lower than the initial values, regardless of the order of the performed treatments.
Cryotherapy applied as a second treatment caused a higher temperature decrease.

When examining a consensual reaction, it was found that applied treatments cause a consensual reaction on the contralateral thigh and it was much more visible after applying the CRYO-US sequence. Here, the gender dependence was observed.

The obtained results may contribute to better planning of the physical treatment, especially in cases where more than one therapy is recommended. Both examined treatments have an anti-inflammatory and analgesic effects. However, they cause different reactions. Therefore, when kinesiotherapy is administered, cryotherapy should be the last treatment, since the temperature decrease lasted longer, facilitating movement and exercises.

Further studies regarding surface temperature distribution in other physical treatments and their combination should be conducted in order to establish a proper personalized therapy, which is more recommended than the standard protocols [21, 22].

Open Access This article is distributed under the terms of the Creative Commons Attribution 4.0 International License (http://crea tivecommons.org/licenses/by/4.0/), which permits unrestricted use, distribution, and reproduction in any medium, provided you give appropriate credit to the original author(s) and the source, provide a link to the Creative Commons license, and indicate if changes were made.

\section{References}

1. Fernandez-Cuevas I, Bouzas Marins JC, Lastras JA, Gomez Carmona PM, Cano SP, Garcia-Concepcion MA, Sillero-Quintana M. Classification of factors influencing the use of infrared thermography in humans: a review. Infred Phys Technol. 2015;71:28-55.

2. Ring EFJ. Pioneering progress in infrared imaging in medicine. Quant Infrared Termogr J. 2014;11:57-65.

3. Jones BF, Plassmann P. Digital infrared thermal imaging oh human skin. IEEE Eng Med Biol Mag. 2002;21:41-8.

4. Ring EFJ, Amer A. Infrared imaging in medicine. Physiol Meas. 2012;33:33-46.

5. Maksymowicz K, Dudek K, Bauer J, Jurek T, Drozd R. Assessment of the possibility of application of the thermovision technique in medico-legal diagnosis. Theoretical basis. Ann Acad Med Stetin. 2007;53(2):102-6.

6. Bauer J, Dereń E. Standardization of infrared thermal imaging in medicine and physiotherapy. Acta Bio Opt Inf Med. 2014;20(1): 11-20.

7. Bauer J, Mazurkiewicz J. Neural network and optical correlators for infrared imaging based face recognition. In: Kwasnicka $\mathrm{H}$, Paprzycki M, editors. Intelligent systems design and applications M. Los Alamitos: IEEE Computer Society Press; 2005. p. 234-8.

8. Robertson V, Ward A, Low J, Redd A. Electrotherapy explained. Principles and practice. 4 th ed. Oxford: Butterworth-Heinemann Elsevier Health Science; 2006.

9. Johnson JM, Kellogg DL Jr. Local thermal control of the human cutaneous circulation. J Appl Physiol. 2010;109:1238-99. 
10. Bracciano AG. Physical agent modalities: theory and application for the occupational therapist. Thorofare: SLACK Incorporated; 2008.

11. Nadler SF, Weingand K, Kruse RJ. The physiologic basis clinical applications of cryotherapy and thermotherapy for the pain practitioner. Pain Phys. 2004;7(3):395-9.

12. Bauer J, Skrzek A. Physiological principles of cryotherapy. In: Podbielska H, Stręk W, Biały D, editors. Whole body cryotherapy. Wrocław: Kriotechnika Medyczna; 2006. p. 21-6.

13. Cholewka A, Stanek A, Sieroń A, Drzazga Z. Thermography study of skin response due to whole-body cryotherapy. Skin Res Technol. 2012;18(2):180-7.

14. Cholewka A, Drzazga Z, Sieroń A, Stanek A. Thermovision diagnostics in chosen spine diseases treated by whole body cryotherapy. J Therm Anal Calorim. 2010;102:113-9.

15. Baker KG, Robertson VJ, Duck FA. A review of therapeutic ultrasound: biophysical effects. Phys Therapy. 2001;81(7):1351-8.

16. Ratajczak B, Boerner E, Demidaś A, Tomczyk K, Dębiec-Bąk A, Hawrylak A. Comparison of skin surface temperatures after ultrasounds with use of paraffin oil and ultrasounds with use of gel. J Therm Anal Calorim. 2012;109(1):387-93.

17. Cholewka A, Stanek A, Wojcik M, Sieron-Stoltny K, Drzazga Z. Does local cryotherapy improve thermal diagnosis similar to whole-body cryotherapy in spinal diseases? J Therm Anal Calorim. 2017;127:1155-62.
18. Boerner E, Bauer J, Ratajczak B, Dereń E, Podbielska H. Application of thermovision for analysis of superficial temperature distribution changes after physiotherapy. J Therm Anal Calorim. 2015;120:262-7.

19. Rutkowski R, Straburzyńska-Lupa A, Korman P, Romanowski W, Gizińska M. Thermal effectiveness of different IR radiators employed in rheumatoid hand therapy as assessed by thermovisual examination. Photochem Photobiol. 2011;87(6):1442-6.

20. Boerner E, Bauer J, Kuczkowska M, Podbielska H, Ratajczak B. Comparison of the skin surface temperature on the front of thigh after application of combined red-IR radiation and diadynamic currents executed in a different sequence. J Therm Anal Calorim. 2015;120(1):921-8.

21. Bubnov RV, Strokan AM, Logvinchuk PV, Aleksieieva TS. Personalized monotherapy vs. protocol therapy complex for frozen shoulder. Comparative study. EPMA J. 2014;5(Suppl 1):A163. doi:10.1186/1878-5085-5-S1-A163.

22. Costigliola V. Healthcare overview: global process of personalisation in medicine. EPMA J. 2010;1:525. doi:10.1007/s13167010-0059-5. 